\title{
SISTEM INFORMASI TRACER STUDY ALUMNI UNIVERSITAS ISLAM INDRAGIRI BERBASIS WEB
}

\author{
'Ahmad Rusli, ${ }^{2}$ llyas \\ 1,2 Program Studi Sistem Informasi, Fakultas Teknik dan Ilmu Komputer \\ Universitas Islam Indragiri (UNISI) \\ Jl. Provinsi , Parit 1 Tembilahan Hulu, Tembilahan, Riau \\ Email:amd.rusli93.ar@gmail.com, daengilyas01@gmail.com
}

\begin{abstract}
ABSTRAK
Perguruan tinggi sangat membutuhkan informasi mengenai data alumni, keberadaan alumni merupakan bagian integral dari perguruan tinggi atau institusi pendidikan, melalui profil alumni, kita dapat menilai dan membuktikan kualitas sebuah institusi pendidikan. Tracer Study merupakan salah satu sarana yang digunakan untuk menelusuri informasi alumni dan mampu menyediakan berbagai informasi yang bermanfaat seperti data pribadi, riwayat pendidikan ataupun informasi riwayat pekerjaan. Dapat disimpulkan bahwa dengan adaya system informasi Tracer Study ini diharapkan dapat memantau keberadaan alumni dan mempermudahkan dalam mendata alumni serta dapat menyajikan informasi secara efisien.
\end{abstract}

Kata Kunci: Sistem Informasi, Tracer Studi, Web

\section{PENDAHULUAN}

Perkembangan teknologi informasi dalam dekade terakhir ini memberikan pengaruh yang sangat besar terhadap berbagai aspek kehidupan terutama di perguruan tinggi, dalam suatu institusi akademis menjadi kebutuhan yang harus diutamakan karena berdampak langsung terhadap kepuasan pengguna akan terpenuhinya kebutuhan mereka. Tingkat kualitas pelayanan menjadi indikator kualitas sebuah institusi akademis dan dapat berfungsisebagai media publikasi yang efektif. Salah satu keunggulan teknologi web adalah mampu dioperasikan pada komputer desktop, jaringan lokal (LAN), intranet, maupun internet. Keuntungannya memungkinkan aplikasi dapat dimanfaatkan tanpa proses instalasi pada komputer pengguna. Kedua hal tersebut memungkinkan user untuk menjalankan kegiatan desktop dan online sekaligus.

Pada saat ini banyak perguruan tinggi telah memanfaatkan teknologi web dalam menyampaikan informasi dan promosi karena lebih efektif. dikarenakan meningkatnya pengguna internet. Dilihat dari segi pentingnya sebuah kualitas layanan, untuk meningkatkan fungsi pelayanan Universitas Islam Indragiri khususnya Fakultas Pertanian maka sistem pelacakan merupakan salah satu betuk pelayanan. Hal ini dikarenaka meningkatnya jumlah alumni yang dihasilkan pada setiap wisuda Universitas Islam Indragiri. Sehingga untuk mencari dan mendapatkan informasi tentang alumni membutuhkan waktu cukup lama karena system pendataan yang digunakan masih manual, hal ini sangat menyulitkan bagi pihak universitas.

Berdasarkan latar belakang penelitian maka dirumuskan masalah antara lain: (1)Belum adanya sistem yang membangun tentang tracer study alumni fakultas pertanian yang berbasis web. (2)Kesulitannya fakultas pertanian dalam melakukan pencarian data alumni sehingga memakan waktu yang lama. (3)Sulitnya mengakses data alumni fakultas pertanian universitas islam indragiri.

Agar permasalahan tidak meluas, lebih terarah dan tidak menyimpang dari permasalahan yang ada, maka permasalahannya hanya dibatasi pada : (1)Sistem informasi yang di bangun hanya akan mengolah informasi data alumni yang ada di Fakultas Pertanian Universitas Islam Indragiri. (2)Sistem informasi akan menginput dan menampilkan informasi mengenai data alumni. (3)Bahasa pemrograman yang akan digunakan untuk membangun sistem informasi tracer study alumni adalah PHP dengan database yang digunakan adalah MySQL. 
Adapun tujuan penulisan antara lain adalah : Untuk merancang sebuah sistem inforamasi alumni berbasis web dengan harapan di peroleh manfaat tersedianya informasi data-data alumni sehingga dapat membantu dalam melakukan pelacakan alumni. Manfaat penelitian yang diperoleh dari sistem informasi tracer study alumni fakultas pertanian universitas islam indragiri berbasis web yaitu : (1)Untuk menghasilkan suatu informasi tracer study alumni fakultas pertanian berbasis web yang terkomputernisasi. (2)Untuk memudahkan mahasiswa alumni fakultas pertanian dalam melakukan registrasi alumni. (3)Untuk memeberiakan kemudahan fakultas pertanian dalam melakukan pencarian data alumni.

\section{TINJAUAN PUSTAKA}

Sistem menurut[1] adalah kumpulan atau himpunan dari unsur atau variabel-variabel yang saling terkait, saling berinteraksi, dan saling tergantung satu sama lain untuk mencapai tujuan. Selain itu sistem juga dapat didefinisikan sebagai sekumpulan objek-objek yang saling berelasi dan berinteraksi serta hubungan antar objek bisa dilihat sebagai satu kesatuan yang dirancang untuk mencapai satu tujuan yang telah ditetapkan. Sedangkan menurut[2] dalam bukunya mendefenisikan informasi sebagai data yang telah diolah menjadi bentuk yang lebih berarti dan berguna bagi penerimanya untuk mengambil keputusan masa kini maupun yang akan datang. Sedangkan menurut Raymond McLeod (1995) mendefenisikan informasi sebagai data yang telah diolah menjadi bentuk yang lebih berarti bagi penerimanya Seperti disebutkan sebelumnya, sistem informasi adalah seperangkat elemen atau komponen yang saling terkait yang mengumpulkan (input), memanipulasi (process), menyimpan dan menyebarkan (output) data dan informasi, dan memberikan reaksi korektif (mekanisme umpan balik) untuk memenuhi tujuan, mekanisme umpan balik adalah komponen yang membantu organisasi mencapai tujuan mereka, seperti meningkatkan laba atau meningkatkan layanan pelanggan[3].

Klasifikasi Sistem menurut[4] Sistem merupakan suatu bentuk integrasi antara satu komponen dengan komponen lain karena sistem memiliki sasaran yang berbeda untuk setiap kasus yang terjadi di dalam sistem tersebut. Oleh karena itu sistem dapat diklasifikasikan dari beberapa sudut pandangan, seperti contoh sistem yang bersifat abstrak, sistem alamiah, sistem yang bersifat deterministik, dan sistem yang bersifat terbuka dan tertutup. (a) Sistem abstrak dan sistem fisik. Sistem abstrak adalah sistem yang berupa pemikiran atau ide-ide yang tidak tampak secara fisik, misalnya sistem teologi, yaitu suatu system yang berupa pemikiran tentang hubungan antara manusia dengan Tuhan sedangkan sistem fisik merupakan sistem yang ada secara fisik, seperti sistem komputer, sistem produksi, sistem penjualan, sistem administrasi personalia, dan lain sebagainya. (b) Sistem alamiah dan sistem buatan manusia. Sistem alamiah adalah sistem yang terjadi melalui proses alam, tidak dibuat oleh manusia, misalnya sistem perputaran bumi, terjadinya siang malam, dan pergantian musim. Sedangkan sistem buatan manusia merupakan sistem yang melibatkan ubungan manusia dengan mesin, yang disebut dengan human machine system. Sistem informasi berbasis komputer merupakan contohnya, karena menyangkut penggunaan komputer yang berinteraksi dengan manusia. (c) Sistem deterministik dan sistem probabilistic. Sistem yang beroprasi dengan tingkah laku yang dapat diprediksi disebut sistem deterministik. Sistem komputer adalah contoh dari sistem yang tingkah lakunya dapat dipastikan berdasarkan program-program komputer yang dijalankan. Sedangkan sistem yang bersifat probabilistik adalah sistem yang kondisi masa depannya tidak dapat diprediksi, karena mengandung unsur probabilitas. (d) Sistem terbuka dan sistem tertutup. Sistem tertutup merupakan sistem yang tidak berhubungan dan tidak terpengaruh oleh lingkungan luarnya. Sistem ini bekerja. secara otomatis tanpa ada campur tangan dari pihak luar. Sedangkan sistem terbuka adalah sistem yang berhubungan dan dipengaruhi oleh lingkungan luarnya, yang menerima masukan dan menghasilkan keluaran untuk subsistem lainnya. 


\subsection{Metode Penelitian}

UML adalah singkatan dari Unified Modeling Language yang berarti bahasa pemodelan standar merupakan salah satu alat bantu yang sangat handal di dunia pengembangan sistem yang berorientasi obyek. UML dapat pula digambarkan oleh beberapa orang sebagai "bahasa rekayasa perangkat lunak. Hal ini disebabkan karena UML menyediakan bahasa pemodelan visual yang memungkinkan bagi pengembang sistem untuk membuat blue print atas visi mereka dalam bentuk yang baku, mudah dimengerti serta dilengkapi dengan mekanisme yang efektif untuk berbagi dan mengkomunikasikan rancangan mereka dengan yang lain. Tujuan UML adalah untuk menyediakan arsitek sistem, insinyur perangkat lunak, dan pengembang perangkat lunak dengan alat untuk analisis, perancangan, dan implementasi sistem berbasis softwarenya serta untuk pemodelan bisnis dan sejenisnya, proses. Versi awal UML (UML 1) berasal dari tiga metode berorientasi objek utama (Booch, OMT, dan OOSE). dan menggabungkan sejumlah praktik terbaik dari desain bahasa pemodelan, pemrograman berorientasi obyek, dan bahasa deskripsi arsitektural. Sehubungan dengan UML 1, UML melakukan revisi mengikatkan dengan mendefinisikan aturan dan semantik abstrak yang lebih tepat secara presisi, struktur bahasa yang lebih modular, dan kemampuan yang sangat baik untuk memodelkan sistem berskala besar. Salah satu tujuan utama UML adalah memajukan keadaan industri dengan memungkinkan interoperabilitas alat pemodelan visual objek visual. Namun, untuk memungkinkan pertukaran informasi model antara alat, kesepakatan semantik dan notasi diperlukan. UML memenuhi persyaratan berikut: Definisi formal dari metamodel berbasis MOF yang umum yang menentukan sintaks abstrak UML. Sintaks abstrak mendefinisikan himpunan konsep pemodelan UML, atribut dan relasinya, serta aturan untuk menggabungkan konsep-konsep ini untuk membangun model UML parsial atau lengkap. Penjelasan rinci tentang semantik setiap konsep pemodelan UML. Semantik mendefinisikan, dengan cara teknologi yang independen, bagaimana konsep UML harus direalisasikan oleh komputer. Spesifikasi elemen notasi yang dapat dibaca manusia untuk mewakili konsep pemodelan UML individual serta aturan untuk menggabungkannya ke dalam berbagai jenis diagram yang berbeda sesuai dengan aspek sistem model yang berbeda. Definisi rinci tentang cara alat UML dapat dibuat sesuai dengan spesifikasi ini. Ini didukung (dalam spesifikasi terpisah) dengan spesifikasi berbasis XML dari format interchange model yang sesuai (XMI) yang harus direalisasikan oleh alat yang sesuai menurut [5].

Dalam pengembangan sistem informasi, salah satu model dinamakan siklus hidup pengembangan sistem (Systems Development Life Cycle/SDLC) yang memuat langkah-langkah yang semestinya diikuti dalam perancangan basis data dan pemrogram, untuk menspesifikasikan, mengembangkan, serta memelihara sistem informasi. Proses ini sering digambarkan secara bertingkat seperti yang diperlihatkan pada gambar 2 Metafora bertingkat atau air terjun (waterfall) digunakan untuk menggambarkan bahwa keluaran dari suatu tahap merupakan masukan untuk tahap berikutnya. Walaupun demikian, seperti yang diperlihatkan di gambar 2 proses ini tidak benar-benar berjalan secara linear, suatu tahap mungkin berjalan secara parallel serta dimungkinka untuk kembali pada langkah berikutnya (proses iterasi) saat suatu keputusan tertentu perlu dipertimbangkan kembali (Nugroho, 2011)[6].

Tracer Study menurut[7]yang mengutip dari Schomburg adalah penelitian mengenai lulusan dari suatu perguruan tinggi atau menurut BAN-PT yakni penelusuran alumni untuk menggali informasi melalui pengisian kuesioner yang disusun sedemikian rupa untuk tujuan perbaikan kurikulum dan proses pendidikan di suatu sekolah Tracer study termasuk ke dalam standar ketiga dari ketujuh standar dalam Standar Akreditasi Program Sarjana yakni Mahasiswa dan Lulusan, sehingga untuk poin lulusan dapat ditelusuri dengan kegiatan tracer study. Berdasarkan buku terbitan BAN-PT untuk data-data mengenai lulusan berisi mengenai berbagai faktor berikut :

1. Profil lulusan : ketepatan waktu penyelesaian studi, proporsi mahasiswa yang menyelesaikan studi dalam batas masa studi

2. Layanan dan pendayagunaan : lulusan, ragam, jenis, wadah, mutu, harga, intensitas. 
3. Pelacakan dan perekaman data lulusan : kekomprehensifan, pemutakhiran, profil masa tunggu kerja pertama, kesesuaian bidang kerja dengan bidang studi, dan posisi kerja pertamaPartisipasi lulusan dan alumni dalam mendukung pengembangan akademik dan nonakademik program studi.

\subsection{Prangakat Lunak Yang Digunakan}

PHP merupakan singkatan dari "Hypertext Preprocessor". Pada awalnya PHP merupakan kependekan dari Personol Home Page (Situs Personal) dan PHP itu sendiri pertama kali dibuat oleh Rasmus Lerdorf pada tahun 1995, dan pada saat PHP masih bernama FI (Form Interpreter), yang wujudnya berupa sekumputan script yang digunakan untuk mengotah data form dari web. Selanjutnya Rasmus meritis kode Sumber tersebut untuk umum. PHP adalah sebuah bahasa scripting yang terpasang pada HTML. Sebagian besar sintaksnya meirip dengan bahasa pemograman C, Java, asp, dan Perl, ditambah beberapa fungsi PHP yang spesifik dan mudah dimegerti. Dari uraian diatas maka dapat diambil 4 point utama tentang PHP :

1. PHP adalah singkatan dari Hypertext Preprocessor

2. PHP adalah bahasa scripting server-side, artinya dijalankan di server, kemudian outputnya dikerim ke client (browser.

3. PHP digunakan untuk aplikasi web.

4. PHP mendukung banyak database (MySQL, Informix, Oracle, Sybase, Solid, postreSQL, Generik ODBC, dII)

Jadi anda tidak perlu susah-susah menampilkan postingan anda dengan cara lama. Yaitu dengan cara link ke file lain atau menganti file a dengan file b. dengan PHP anda juga dapat menampikkan beberapa data dalam 1 file, jadi tidak repot-repot membuat file baru. Anda dapat membuat 1 dile tetapi dalam 1 file itu bias menampilkan banyak data. Yaitu dengan bantuan database. (Madcoms, 2011)[8]

Web adalah suatu layanan informasi di internet yang berbasis grafis dan memungkinkan siapapun untuk berada 24 jam/sehari di internet. Jenis-jenis web menurut kamus istilah internet penerbit Wahana Komputer Semarang adalah sebagai berikut: (1) Web Browser, web browser adalah suatu program dimana kita dapat mengambil dokumen-dokumen HTML dari web server dengan menggunakan protokol dan format HTTP yang satu ke yang lainnya di web server yang sama atau di server lain, misalnya : Internet Explorer, Opera. (2) Web Edit, web edit adalah editor teks HTML berbasis Windows, seperti : Ms. Front Page, NotePad. (3) Web Page, web page adalah kemasan yang berisi suara, grafis, film dan teks yang berasal dari file-file data HTML. (4)Web Server, web server adalah sistem komputer di suatu organisasi yang berfungsi sebagai server untuk fasilitas WWW, dan dapat diakses oleh seluruh pemakai internet, seperti PWS, IIS, dan Apache. (5) Website, website adalah lokasi-lokasi yang berada di internet. Website juga merupakan tempat atau alamat di internet yang merupakan sampul halaman yang berisi sebuah situs web (Hasibun, 2010) [9]

Menurut (Sudarmaji, 2015) HTML Adalah kependekan dari Hypertext Markup Language adalah sebuah bahasa markup yang digunakan untuk membuat sebuah halaman web dan menampilkan berbagai informasi di dalam sebuah browser Internet. PHP (PHP Hypertext preprocessor) adalah bahasa server side scripting yang menyatu dengan HTML untuk membuat halaman web yang dinamis. Tujuan utama pada bahasa pemrograman PHP dalam untuk memungkinkan perancang web untuk menulis web dinamik secara cepat. Penemu bahasa pemrograman ini adalah Rasmus Lerdort yang bermula dari keinginan kesederhanaan ahli tersebut untuk mempunyai alat bantu ( tools ) dalam memonitoring penggunjungnya yang memilih situs pribadinya. Itulah sebabnya pada awal pengembangannya PHP merupakan personal Home Page tools, sebelumnya akhirnya menjadi PHP ( PHP Hypertext Prepocessor)[10].

MySQL adalah sebuah perangkat lunak sistem manajemen basis data SQL (bahasa Inggris: database management system) atau DBMS yang multithread, multi-user, dengan sekitar 6 juta instalasi di seluruh dunia. MySQL AB membuat MySQL tersedia sebagai perangkat lunak gratis 
dibawah lisensi GNU General Public License (GPL), tetapi mereka juga menjual dibawah lisensi komersial untuk kasus-kasus dimana penggunaannya tidak cocok dengan penggunaan GPL[11].

XAMPP adalah sebuah software web server apache yang didalamnya sudah tersedia database server mysql dan support php programming. XAMPP merupakan software yang mudah digunakan, gratis dan mendukung instalasi di Linux dan Windows. Keuntungan lainnya adalah cuma menginstal satu kali sudah tersedia Apache Web Server, MySQL Database Server, PHP Support (PHP 4 dan PHP 5) dan beberapa module lainnya. Hanya bedanya kalau yang versi untuk Windows sudah dalam bentukinstalasi grafis dan yang Linux dalam bentuk file terkompresi. Kelebihan lain yang berbeda dari versi untuk Windows adalah memiliki fitur untuk mengaktifkan sebuah server secara grafis, sedangkan Linux masih berupa perintah-perintah di dalam console. Oleh karena itu yang versi untuk Linux sulit untuk dioperasikan [12]

\subsection{Pengujian Sistem}

Pengujian perangkat lunak adalah elemen kritis dari jaminan kualitas perangkat lunak dan merepresentasikan kajian pokok dari spesifikasi, desain, dan pengkodean. Sejumlah aturan yang berfungsi sebagai sasaran pengujian pada perangkat lunak adalah (1)Pengujian adalah peroses eksekusi suatu program dengan maksud menemukan kesalahan. (2)Test case yang baik adalah test case yang memiliki probabilitas tinggi untuk menemukan kesalahan yang belum pernah ditemukan sebelumnya. (3)Pengujian yang sukses adalah pengujian yang mengungkap semua kesalahan yang belum pernah ditemukan sebelumnya.

Karakteristik umum dari pengujian perangkat lunak adalah sebagai berikut:(1)Pengujian dimulai pada level modul dan bekerja keluar kearah integrasi pada sistem berbasiskan komputer. (2)Teknik pengujian yang berbeda sesuai dengan poin-poin yang berbeda pada waktunya. (3)Pengujian diadakan oleh software developer dan untuk proyek yang besar oleh group testing yang independent. (4)Testing dan Debugging adalah aktivitas yang berbeda tetapi debuggingharus diakomodasikan pada setiap strategi testing.

Metode pengujian perangkat lunak ada 3 jenis, yaitu (Sukamto, 2009): (1)White Box/Glass Box - pengujian operasi. (2)Black Box - untuk menguji system. (3)Use case - untuk membuat input dalam perancangan black box dan pengujian statebased(Sukamto, 2009) [13].

Black Box Testing berfokus pada spesifikasi fungsional dari perangkat lunak. Tester dapat mendefinisikan kumpulan kondisi input dan melakukan pengetesan pada spesifikasi fungsional program. Black Box Testing bukanlah solusi alternatif dari White Box Testing tapi lebih merupakan pelengkap untuk menguji hal-hal yang tidak dicakup oleh White Box Testing (Mustaqbal, 2015) [14].

White Box Testing adalah salah satu cara untuk menguji suatu aplikasi atau software dengan cara melihat modul untuk dapat meneliti dan menganalisa kode dari program yang di buat ada yang salah atau tidak. Kalau modul yang telah dan sudah di hasilkan berupa output yang tidak sesuai dengan yang di harapkan maka akan dikompilasi ulang dan di cek kembali kode-kode tersebut hingga sesuai dengan yang diharapkan. Kelemahan White Box Testing adalah pada perangkat lunak yang jenisnya besar, metode white box testing ini dianggap boros karena melibatkan banyak sumberdaya untuk melakukannya[15].

\section{PERANCANGAN SISTEM}

\subsection{Use Case Diagram}

Use case diagram adalah pemodelan yang menggambarkan kelakuan dari aplikasi yang dibuat, mendeskripsikan interaksi antar actor. Gambaran urutan transaksi atau proses didalam sistem. 


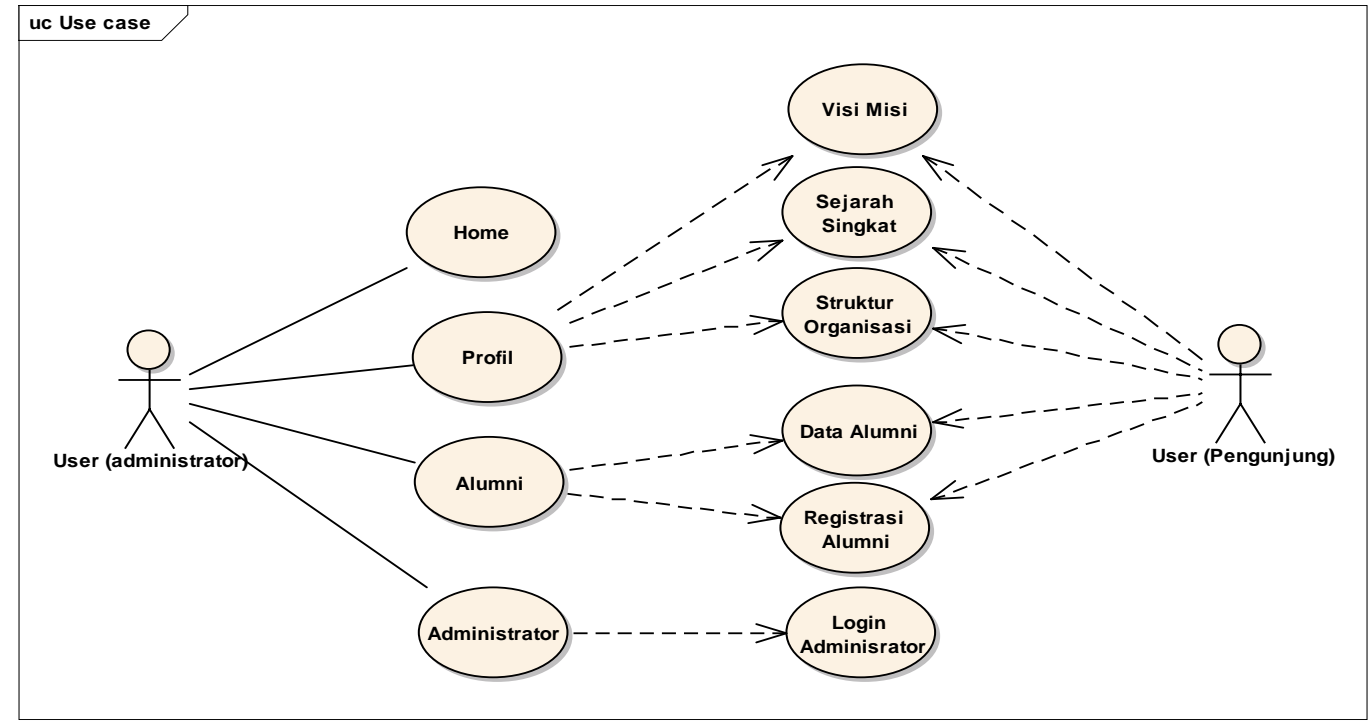

\section{Gambar 1. Alumni Case Diagram Sistem}

Pada gambar diatas dapat dijelaskan bahwa dalam sistem yang dibangun hanya terdapat dua aktor yaitu administrator. Admin memiliki hak penuh terhadap sistem atau memanipulasi atau mengelola sistem. Sedangkan pengunjung adalah seseorang yang melakukan akses terhadap website sistem informasi alumni.

\subsection{Use Case Diagram Registrasi Alumni}

Use Case Diagram Registrasi Alumni merupakan perancagan proses registrasi Alumni, dapat dilihat pada gambar Berikut ini :

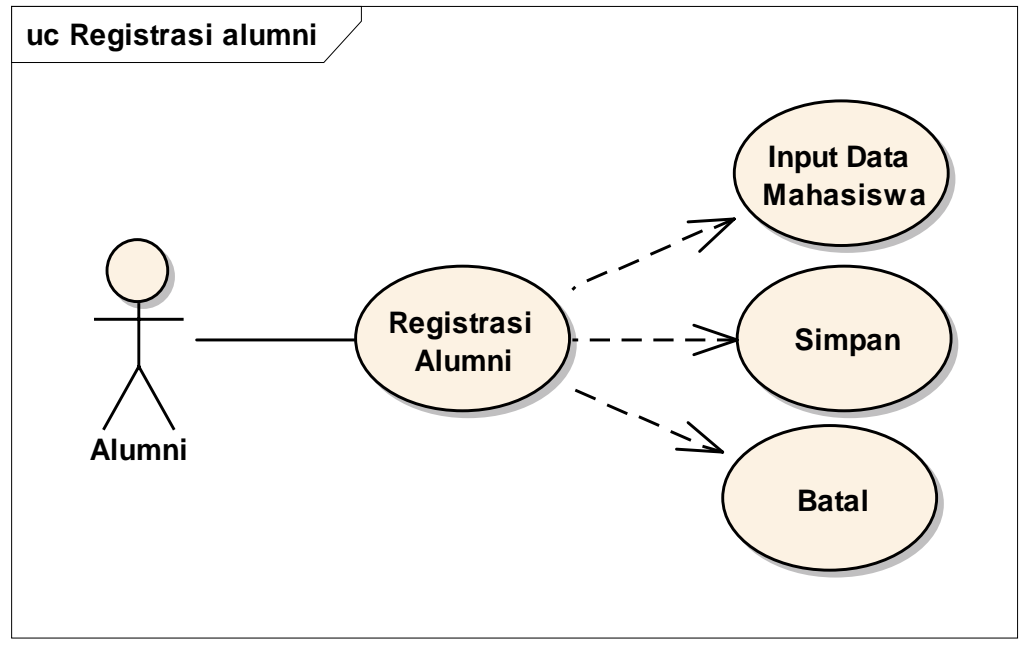

\section{Gambar 2. Use Case Diagram Registrasi Alumni}

Berdasarkan gambar 2 dapat dijelaskan alumni case diagram registrasi alumni yaitu Auntuk memulai seorang alumni harus melakukan pendaftaran terdahulu, alumni harus memasukkan biodata alumni. Setelah semua telah terisi, alumni bisa klik simpan untuk menyimpan data yang telah diinputkan atau klik batal jika data ada yang belum terisi. Lalu keluar.

\section{IMPLEMENTASI SISTEM}

\subsection{Halaman Utama Aplikasi}

Halaman utama merupakan halaman yang pertama tampil ketika pengguna masuk system tracer study. Adapun tampilannya dapat dilihat pada gambar berikut : 


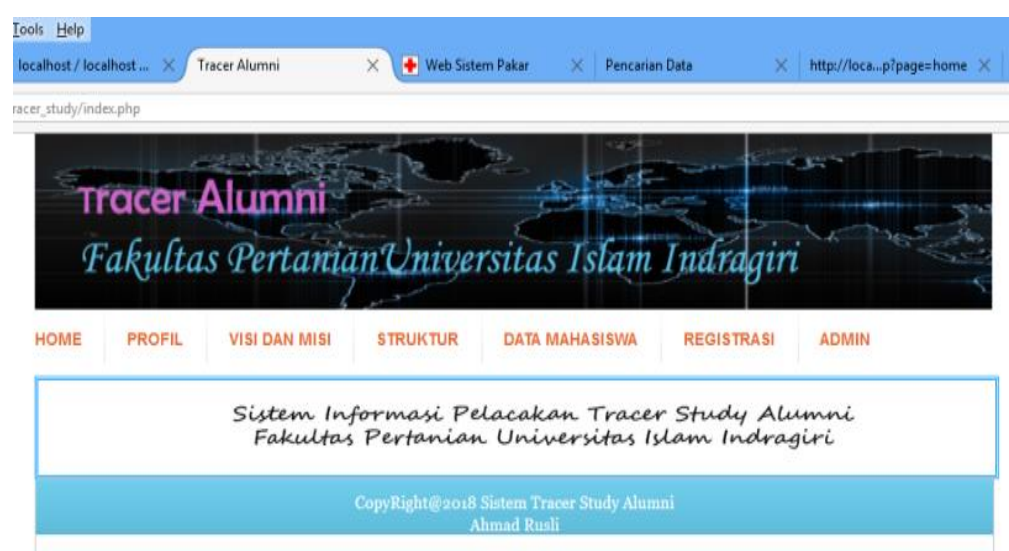

\section{Gambar 3. Halaman Utama Tracer Study}

Halaman profil adalah halaman yang berisikan tentang sejarah Universitas Islasm Indragiri dapat dilihat pada gambar berikut ini:

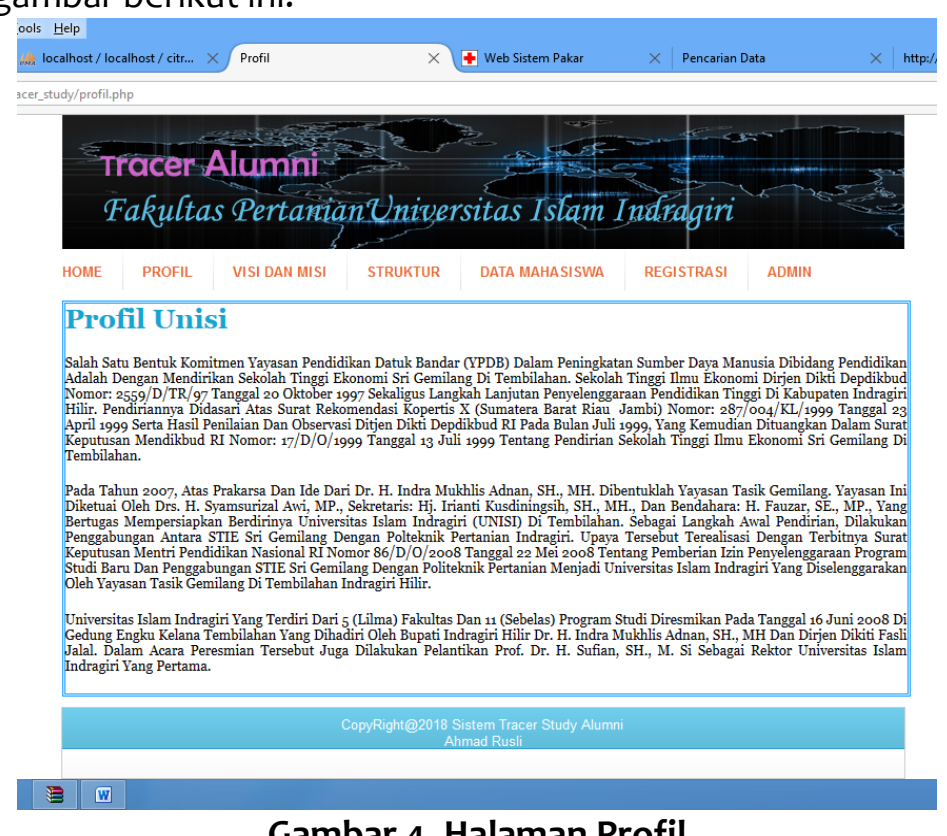

\section{Gambar 4. Halaman Profil}

Halaman visi dan misi merupakan halaman yang berisikan tentang visi dan misi Universitas Islam Indragiri yang dapat di akses oleh penggunjung dengan mengclik Profil .dapat dilihat sebagai berikut.
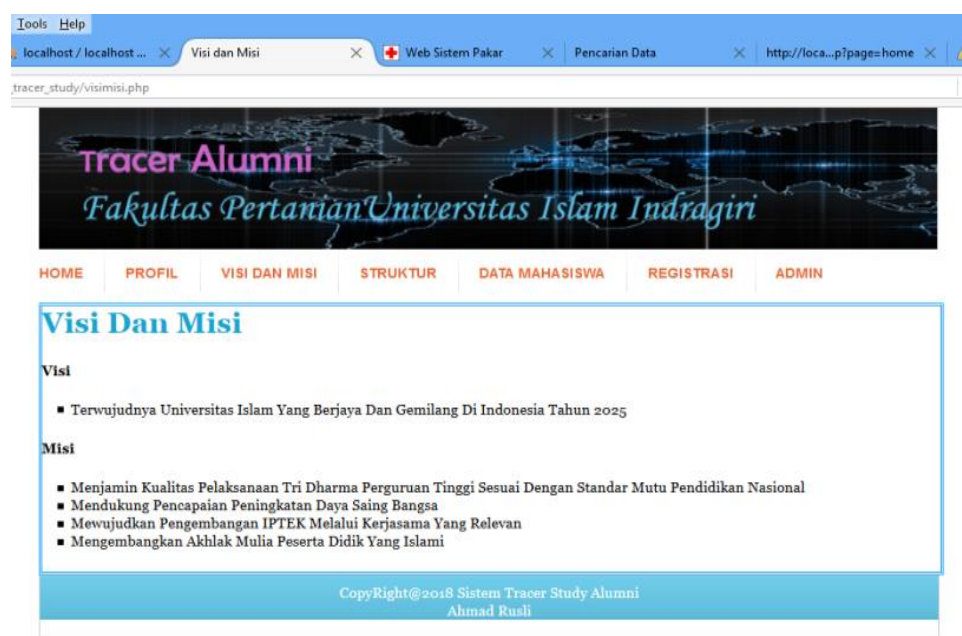

Gambar 5. Halaman Sejarah Singkat UNISI

Rusli, Sistem Informasi Tracer Study Alumni Universitas Islam Indragiri Berbasis Web 
Halaman ini berisikan tentang registrasi alumni, halaman ini dapat di akses oleh pengunjung denga memilih menu tegistrasi pada halaman utama website, dapat dilihat pada gambar berikut ini :

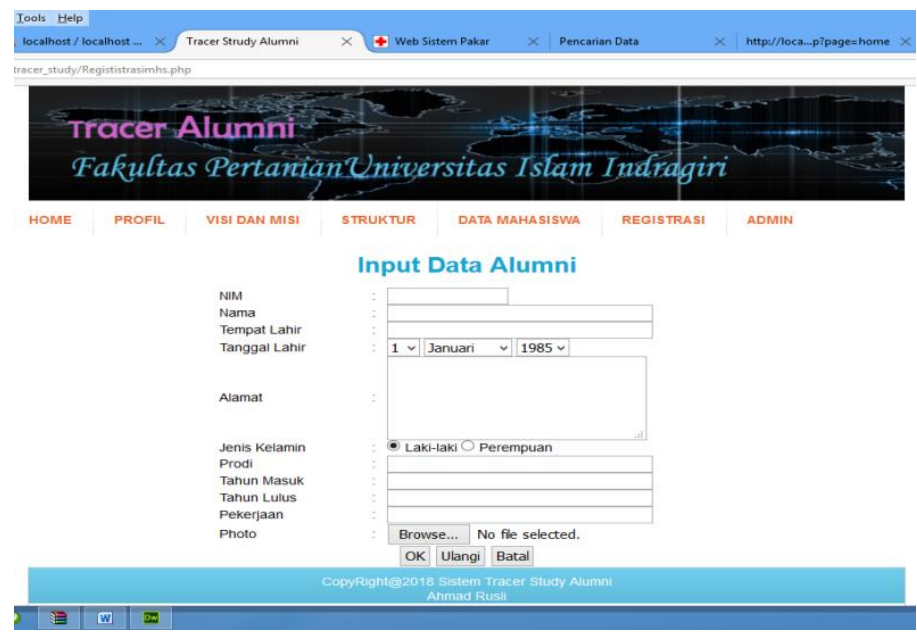

\section{Gambar 6. Halaman Registrasi}

\subsection{Halaman Utama Administrator}

Halaman utama administrator merupakan halaman yang hanya apat di akses oleh administrator halaman ini digunakan untuk megelola data alumni universitas islam indragiri khususnya fakultas pertanian. Tampilan dapat dilihat pada gambar berikut :

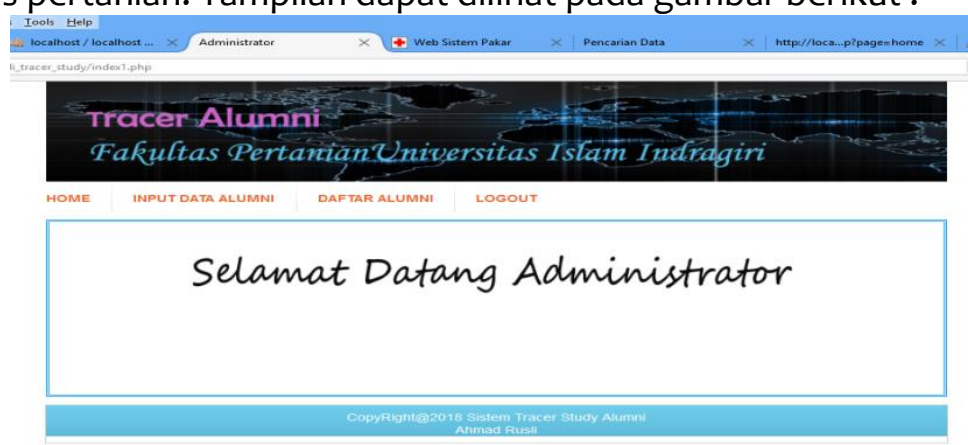

Gambar 7. Halaman Utama Administrator

Halaman input data alumni merupakan halaman yang digunakan oleh administrator untuk menginputkan data alumni universitas Islam Indragiri. Adapun tampilanya dapat dilihat pada gambar Berikut :
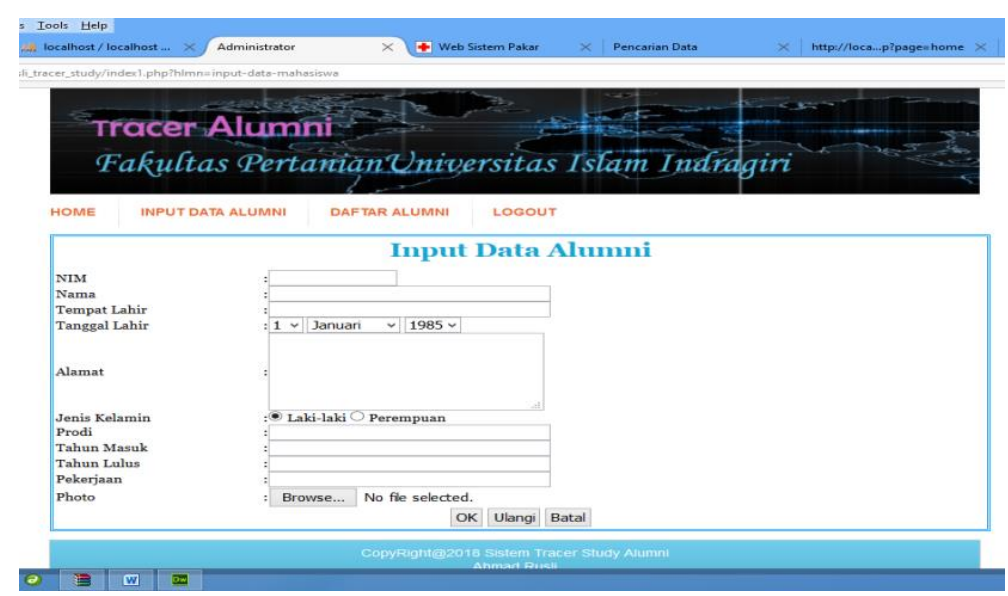

Gambar 8. Input Data Alumni

Rusli, Sistem Informasi Tracer Study Alumni Universitas Islam Indragiri Berbasis Web 
Halaman Daftar alumni merupakan halaman yang berisikan seluruh data alumni. Dan dapat digunanakan untuk mengedit data alumni jika ada perubahan atau kesalahan pada penginputan data alumni. Adapun tampilannya dapat dilihat pada gambar berikut ini :

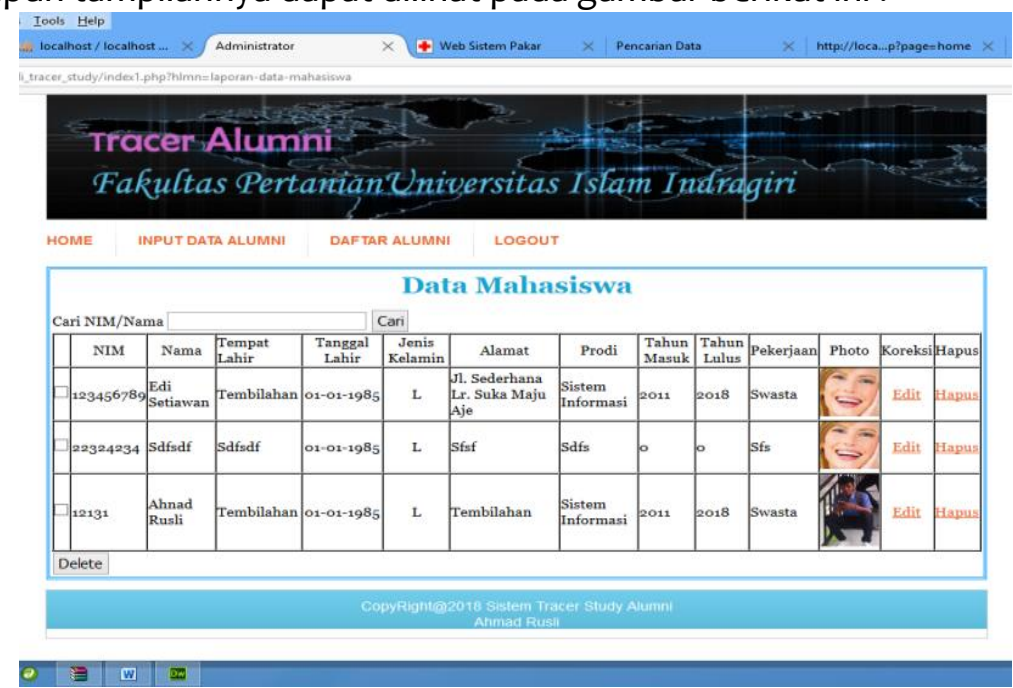

Gambar 9. Data Alumni

\section{KESIMPULAN}

Dari hasil uraian dalam bab-bab sebelumnya mengenai sistem informasi tracer study alumni Universitas Islam Indragiri Fakultas Pertanian berbasis web ini, maka dapat diambil beberapa kesimpulan yaitu:

1. Sistem Informasi tracer studi alumni yang dibuat dapat melacak keberadaan alumni Universitas Islam Indragiri.

2. Sistem informasi tracer study alumni yang telah dibuat dapat melakukan komunikasi antar alumni, mahasiswa, dan pihak universitas secara online.

3. Dengan sistem informasi tracer stdudy alumni dapat mempermudah pihak fakultas dan dalam membuat laporan alumni.

Penulisan skripsi ini tentu terdapat banyak kekurangan, yang mungkin dapat disempurnakan lagi pada penelitian-penelitian berikutnya. Maka agar aplikasi ini dapat lebih sempurna lagi, pengembangan aplikasi ini disarankan agar menciptakan aplikasi yang lebih kompleks, sehingga semakin banyak fasilitas dalam web ini yang bisa diberikan ke Alumni.

\section{REFERENSI}

[1] Al-Bahra Bin Ladjamuddin. B, (2005), Analisis dan Desain Sistem Informasi, Graha Ilmu, Yogyakarta.

[2] Ralph M. Stair, \& George W. Reynolds. (2010), Information System (Ninth Edition), Course Technology Cengage Learning

[3] Nugroho. A. (2014). Rekayasa Perangakat Lunak Berorientasi Objek Dengan Metode USDP, Andi, Yogyakarta.

[4] Ade Putra Nanda, “Jurnal J - Click," J. Sist. Inf. Dan Manaj. Inform., vol. 4, no. 2, pp. 1-9, 2017.

[5] H. Purwoko, H. Dhika, and S. M. Arif, "Perancangan Sistem Work Order Dengan Pemodelan Unified Modeling Language Pada PT. XYZ,” Issn, vol. 1, no. 1, pp. 2527-5321, 2017.

[6] “Aplikasi Tracer Study Universitas Madura," Insa. Comtech Inf. Sci. Comput. Technol. J., vol. 1, no. 2, pp. 31-37, 2017.

[7] M. J. Fitzgerald and F. Arda, "DESIGN DAN IMPLEMENTASI E-JURNAL SEBAGAI PENINGKATAN LAYANAN JURNAL DI KOPERTIS WILAYAH 2,” vol. 2010, no. Snati, pp. 46-50, 2010. 
[8] Madcom. (2011). Membongkar Misteri Adobe Dreamweaver CS6 dengan PHP \& MySQL.Madiun: Andi

[9] M. P. Sistem, “Rancang bangun majalah kampus online berbasis web," vol. 1, 2015.

[10] Sudarmaji. (2015). Rancang Bangun Majalah Kampus Online Berbasis Web. Jurnal INFORMA Politeknik Indonusa Surakarta, Vol. 1 Nomor 1.

[11] I. A. Watung, A. A. E. Sinsuw, S. D. E. Paturusi, X. B. N. Najoan, and J. T. Elektro-ft, "PERANCANGAN SISTEM INFORMASI DATA ALUMNI," 2014.

[12] S. Pelayanan, O. Pada, S. D. Negeri, K. Bengkulumenggunakan, and A. Dreamweaver, "Hari Aspriyono, Jauhari Dosen Fakultas Ilmu Komputer Universitas Dehasen Bengkulu Website SD Negeri 62 .. ISSN 1858 - 2680 ISSN 1858 - 2680," 1858.

[13] Y. Parassa, M. U. Pesik, and R. Mantala, "Implementasi dan pengujian model responsive website objek wisata provinsi sulawesi utara," no. December 2017, pp. 537-544, 2017.

[14] M. S. Mustaqbal, R. F. Firdaus, and H. Rahmadi, "( Studi Kasus : Aplikasi Prediksi Kelulusan SNMPTN )," Penguji. Apl. Menggunakan Black Box Test. Bound. Value Anal. (Studi Kasus Apl. Prediksi Kelulusan SNMPTN), vol. I, no. 3, p. 34, 2015.

[15] S. Nidhra, "Black Box and White Box Testing Techniques - A Literature Review B LACK BOX AND W HITE B OX T ESTING T ECHNIQUES - A L ITERATURE R EVIEW,” no. June 2012, 2016. 